wound, the opening of which had now become considerably increased in size, and presented a sloughy aspect, a thin, fotid, and bloody discharge escaping; great thirst; loathing of food; hot skin; quick and strong pulse; in short, there were present all the symptoms of a smart attack of inflammatory fever. He was bled to twelve ounces, and a saline mixture, with pills of calomel, tartar-emetic, and hyoscyamus, were prescribed. Fomentations of poppy-heads and chamomile flowers, with bread and linseed-meal poultices, were now substituted, instead of dressings of simple cerate and an evaporating lotion, which had been applied from the time of the casualty.

I will not weary you with a daily report of the progress of the case; suffice it to say, that for three or four following weeks, he continued in a very precarious condition, an irritative form of fever early supervened, and from the profuse discharge and sloughing state of the wound, an early necessity of support became indispensable, such as beef-tea, wine, quinine, and opium.

About the tenth day, the integuments near the spine began to inflame, followed by an abscess which opened externally; consequently a sinus or complete opening through the neck was produced; at the fifth week, a portion of a neckcloth which he wore at the time of the explosion came away.

Several months elapsed before the wounds entirely closed, previous to which two or three small portions of bone were discharged, which I believed to be from the transverse process of the vertebra.

During the reparation of the injury the natural sensibility of the arm was gradually restored, and although the limb continued weak for a considerable period, he has now perfect command of it; and at the present time a large depressed form of scar exists at the front part of the neck, but the one near the spine is almost imperceptible.

Considering the locality and the serious and formidable nature of the injury, it is certainly surprising that the important vessels and nerves should have escaped.

Bolton-le-Moors, Lancashire, 1351.

\section{UTERINE HAMORRHAGE ARRESTED BY THE INJECTION OF COLD WATER.}

By WALTER CHAPMAN, Esq., Surgeon, Lower Tooting.

Is November last I attended, for the first time, Mrs. a parish patient, in her sixth confinement, at the full period of gestation. The patient (who resided near my house) is a small, weak, very delicate woman, and had, during her pregnancy, been subjected to great privations and distress. She informs me that she "flooded" after her last labour. On this occasion the labour itself was quite natural. After the removal of the placenta there was some little hæmorrhage, which induced me to remain with her a considerable time, and to apply very firmly the abdominal pad, \&c., and adopt the ordinary means in such cases. I left her going on well. On visiting her again in about an hour, I found her lying as she had been left, but looking so pale and depressed, that I felt sure either external or internal hæmorrhage had occurred On examination there was very little external loss of blood but the uterus had enlarged very considerably from internal hæmorrhage. I therefore introduced my left hand into the uterus, which was filled with coagulated blood, pressed my fingers through the coagula, and titillated the internal surface of the womb, at the same time making the firmest pressure I could with my right hand externally over the aterus; but this proceeding had no effect on the womb; it did not make the slightest contractile effort. I now immediately sent for a common injecting pint syringe, (and retaining my hand in the uterus,) had it filled with the coldest water that could be procured, and directing the pipe with my right hand into the uterus (with the help of an assistant,) had the water injected. Not till after this had been repeated two or three times did the uterus make any decided contraction, I suppose in consequence of the water not coming in free contact with the internal surface of the organ; but presently it did contract, and on partly withdrawing my hand, a large quantity of coagula was expelled. Still the uterus relaxed again immediately; more water was therefore injected, and after some seven or eight syringefuls had been used-the hand being still kept in, and the pressure or grasping of the uterus by the right hand being continued,-its contraction after the expiration of an hour, or perhaps more, became perfect and perma. nent.

Remarks.-This is the first case that hass come under my care (and I hope it may be the last) in which the uterus has failed to recognise and respond to the stimulus of the hand within its cavity; but so it was in this instance, the organ exactly resembling (as Dr. Tyler Smith has described it) "a washed leather bag." This woman, with the exception of debility, recovered perfectly in the course of ten days or a fortnight without a single unfavourable symptom; and I attribute her well-doing principally to the injection of the cold water, giving, of course, the other means their proper share of credit. Should a similar case again present itself I should not hesitate to adopt the same remedy. On this subject Dr. Blundell says: "But should the bleeding become obstinate, so as to place the life of the patient in danger, you would then be justified in throwing astringent fluids into the uterus, a drachm of alum, for example, being dissolved in a quart of water." Dr. Ramsbotham remarked: "I have seen some cases of dan. gerous hæmorrhage after delivery that had resisted all other means, cease, on a quantity of cold water, to the amount of two or three pints, being pumped into the uterus." The late Mr. Ingleby, of Birmingham, stated: "But in extreme cases, where the uterus has been bulky and flaccid, I have known an active contraction ensue from the injection of very cold water when the presence of the hand has failed to produce it. Gooch used to observe: ' I am never happy when attending a labour, unless I carry my elastic bottle with me." "

I consider this case of importance, as augmenting the number of those which have appeared in THE LANCET, showing the value of the injection of cold water in uterine hæmorrhage, without any unfavourable after-symptom from its em. ployment.

Lower Tooting, 1851

\section{A firror}

OF THE PRACTICE OF

MEDICINE AND SURGERY

IN THB

HOSPITALS OF LONDON.

Nulla est alia pro certo noscendi via, nisi quam plurimas et morborum, et dissectionum historias, tum aliorum proprias, collectas habere et inter se comparare.-Morgagnr. De Sed. et Caus. Morb., lib. 14. Procemium.

\section{ST. BARTHOLOMEW'S HOSPITAL.}

Ectrophia Vesica; (Absence of the Anterior Walls of the Bladder;) Operation; Subsequent Death.

\section{(Under the care of Mr. LLord.)}

"OF all instances in which an arrest of development of parts has taken place during human fotal life, none surpasses in interest or importance that which affects the genito-urinary organs: for, inasmuch as the malformation is in great measure confined to the bladder and urethra, the sufferer from such structural defect may attain mature age,-in the great majority of instances sexually incapacitated,-a burden to himself and repulsive to those around." (Mr. McWhinnie, Medical Gazette, vol. i., 1850, p. 360.) We fully agree with the author of this passage, which forms the introduction to a very instructive paper on malformation of the bladder, and we have lately seen such sad cases in different hospitals of London, that we do not wonder that both patient and surgeon are desirous that a rec. tification should, even at some risk, be attempted.

In the number of this journal for March 15, 1851, we had occasion to mention two cases of congenital malformation of the bladder; one under the care of Mr. T. Wakley, at the Royal Free Hospital; the other under that of Mr. Simon, at St. Thomas's Hospital. The former of these two patients has gone into the country, with one of those excellent apparatuses first introduced by Professor Jurine, of Geneva, success. fully used by Dr. Andrew Bonn, of Amsterdam, in 1788, and greatly improved by Mr. Earle, with which the protruded and tender posterior walls of the bladder are covered and protected from the friction of the clothes, and the urine conveyed by a tube to a receptacle fixed to the calf of the leg. The second has undergone an operation for which instruments of a very ingenious construction were contrived, by means of which the urine will ultimately take its course per rectum. The boy has been for some time under treatment, and we refrain from entering into details, as the case is so important that it deserves, at a future period, when the results are well ascertained, a very full and circumstantial description, 